\title{
Just for the fun of it: Making playgrounds accessible to all children
}

\author{
Jenene Burke $^{1}$ \\ School of Education and Arts, University of Ballarat, Mt Helen, Australia
}

\begin{abstract}
There seems to be growing interest worldwide in the concept of purpose-built public playground facilities that are intended specifically to provide play experiences for all children, regardless of their abilities. As this paper will reveal, the complex principle of inclusion underpins the concept of shared play in inclusive playgrounds. However, despite generally being identified as important, inclusion, particularly for children with impairments within play environments, seems to be often poorly understood and sometimes overlooked in existing literature about children's play in playgrounds. This paper draws attention the current situation surrounding public playground accessibility and teases out two discernible ways of approaching playground provision for people with impairments. The first is technically driven and mandated by guidelines and legislation. The other, is child-centred or community-focused, in which participation in play on a playground is supported as a desirable social activity within a connected, inclusive community. Furthermore, this paper will provide an outline of legislation and policies in Australia that are relevant to inclusive playground provision, along with some approaches that have been adopted in some other countries (notably, the United States and the United Kingdom) to provide playground access for children with impairments.
\end{abstract}

Keywords: playgrounds; inclusion; children’s play; universal access.

\section{Introduction}

The notion that it is desirable for children with impairments and their families to gain unfettered access to public playgrounds, in order for all children to have opportunities to play together, is gaining momentum. This paper will discuss the principle of inclusion as it applies to children's playgrounds. One approach to inclusive playground provision that is based solely on technical standards and enforced regulations may have unintended, negative consequences for users with impairments. In contrast, some commentators and researchers favour the adoption of child-centred or sustainable community-centred approaches to accessibility for all playground users.

The term "playground" in this paper refers to children's public play settings. Such settings often contain play equipment that is purpose-designed and built for children to play on, are generally recognised as being broadly accessible to the public at large and

\footnotetext{
${ }^{1}$ Email: Js.burke@ballarat.edu.au
} 
are typically found in public parks, schools, preschools and some fast food outlets. This is consistent with the definition used by Woolley and Lowe (2012) where the term "play spaces" is used with respect to "outdoor environments that have been specifically designed and designated as a place in which children can play" (p. 2). The paper focuses on inclusion in public playgrounds that are intended for community use, and does not specifically consider school playgrounds.

In this paper, disability is defined according to the social relational understanding of disability, which is a "form of social oppression involving the social imposition of restrictions of activity on people with impairments and the socially engendered undermining of their psycho-emotional well-being” (Thomas, 1999, p. 156). In the social model of disability, a clear distinction is made between the concept of "disability” and the concept of “impairment.” Impairment is an individual's functional limitation, defined as "lacking all or part of a limb, or having a defective limb, organ or mechanism of the body” (Union of the Physically Impaired Against Segregation (UPIAS), 1975, p. 14). Disability, thus, is understood as a socially constructed phenomenon that is due to people with impairments being put in a position of disadvantage because they must overcome barriers that are not impediments to people without impairments. They are disabled by these impediments, which can be found in the environment or in social contexts, and not by their own individual attributes (Finkelstein, 2004).

\section{Inclusion of children in play contexts}

Inclusion is a fundamental principle within any accessible environment and should underpin the notion of shared play and access to environments in general (Nind \& Seale, 2009). In simple terms, the process of inclusion in any environment is about making the environment fit the child, regardless of their abilities, rather than expecting the child to fit into the existing environment.

Inclusive practice starts with the assumption that "everyone belongs" and then, accordingly, the society must find ways of making environments welcoming, constructive and productive for all (Reid \& Valle, 2004, p. 466). The principle of inclusion extends to all, not just those with impairments (Beckman \& Hanson, 2002; Widdows, 1997) and applies to "those of all ages who were marginalised, unproductive and non-participative in society” (Topping \& Maloney, 2005). Keefe (2007) regards inclusion as a respectful response to diversity in a society that is underpinned by the principle of social equality:

Diversity is regarded as an asset from which various cultures, human interests, skills, abilities, life perspectives and life experiences contribute to the rich fabric of culture that forms a community. Respect for difference and relationships that are able to foster a dialogue of difference are features of an inclusive community. Inclusion, therefore, reduces the singular power and status quo of the dominant culture to validate and legitimise the way all groups belong within a society. (p. 28) 
Through inclusion, power inequalities inherent in relationships between those with impairments, as a minority group, and those who do not have impairment are reduced and, furthermore, differences are accepted and validated.

There is some empirical evidence to support the idea that placing children together in inclusive environments ensures acceptance of children with impairments by their nonimpaired peers over time. Children without impairments seem to develop empathy and acceptance of difference (Stalker \& Connors, 2003; Widdows, 1997). Children in inclusive kindergarten settings in Greece and the United States were found to be more accepting of children with impairments than children in non-inclusive settings (Nikolaraizi et al., 2005).

\section{Playgrounds in a "risk-averse" society}

Research on playgrounds is dominated by studies that focus on safety and injury prevention (for example, Hudson, Thompson \& Olsen, 2005; Martin \& Cooper, 2005; Monash University Accident Research Centre, 2005; Pancella, 2004) and which inform the design of playgrounds as reflected in the Australian Standards that apply to playground safety..This dominant emphasis on injury prevention, argue Ball, Gill and Spiegal (2008), Bristow (2004) and Moore (2003), is reflective of an increasingly litigious and "risk averse" society (Gill, 2007) and, importantly, as Bristow (2004) adds, deflects attention away from other important playground design issues such as accessibility, challenge, play value and fun for children. Such emphasis on safety has been criticised particularly as being responsible for the diminution of creative, imaginative and challenging play opportunities presented to children on playground equipment (Ball, Gill \& Spiegal, 2008; Factor, 2004;). Bristow argues that an overcautious culture which, she is convinced, underpins playground provision, is promoted by authorities who provide playgrounds, and is rooted in mistrust of parents (or children themselves) to make commonsense decisions about risk. An important counter argument, that children need opportunities to assess and manage risk and to be presented with challenges, all of which are likely to aid their learning and build character and personality, is advanced by Gill (2007). However, as long as a safety discourse dominates playground research, issues of accessibility and participation are less likely to be taken up as the subject of mainstream studies.

\section{Playgrounds as important sites for children's play}

Several ethnographic studies of children's play in school playgrounds reveal the imaginative and creative nature of children's playworlds (Factor, 2004; Moore, 1986) and the powerful, shared, cultural play lore that is passed on across generations of children (Bishop \& Curtis, 2001; Howard, 1955, 1965; Opie \& Opie, 1959, 1969; Russell, 1986). School playgrounds are the focus of these studies rather than public, purpose-designed playgrounds and this focus highlights the paucity of research into children's play cultures as occurring in and facilitated by playgrounds in environments outside schools. Although revealing the rich, complex play cultures that children become immersed in and contribute to, the studies tend to adopt a universal construction 
of childhood, sometimes with reference to ethnicity or gender of children, but without recognising, including or acknowledging impairment.

Moore (1986) makes the important point that, regardless of the level of use by children, built playgrounds offer "substantial social value to children” (p. 108). Moore asked children to draw pictures of the places that they inhabited. One environment frequently depicted by the children was that of the playground. Moore concludes that children value playgrounds "because they provide clearly identifiable pieces of local turf where they [children] can hang out and meet each other” (p. 108). His research implies that playgrounds are important, child-identified, social places for children.

\section{Playgrounds as welcoming places for children with impairments}

Catering for children with impairments is sometimes seen as an afterthought in playground provision. Often the view is espoused that inclusive features only need to be provided if children with particular impairments are already using the playground. Berry (2001), for example, adopts such a stance in her book Playgrounds that work. Berry and others who agree with her, fail to acknowledge that inclusive playground features are not confined to use by children with impairments but should be enjoyed by all children, and indeed, older people as well. Four key characteristics of creative outdoor play spaces, which apply to all children regardless of ability, are identified by Henniger (1994) and cited in Wellhousen (2002). These characteristics are: healthy risk taking; graduated challenges; promotion of a variety of play types; and provision of opportunities for children to manipulate their environments. Wellhousen argues that these characteristics need to be factored into playground design for all children.

Yuill, Strieth, Roake, Aspden and Todd (2007) based their study of school playgrounds on the idea that inclusive features in playgrounds can be of benefit to all children regardless of their abilities. These researchers examined the impact of a particular newly-designed school playground that aimed to enhance opportunities for peer interaction for children with autism spectrum disorders. The play interactions of eight, five- to seven-year-old boys who had been diagnosed with autism spectrum disorders were videotaped, observed and coded into play interaction types, following their introduction to the new school playground. The new school playground had been designed to support imaginative play and to provide an "appropriate" level of physical challenge, unlike the old one, which was deemed to be "well within all the children's capabilities" (p. 1193). It also had provision for "structured movement" such as a clear circuit around the playground and observation points for children to watch others play but not necessarily to interact. The researchers concluded that careful attention to playground design might ensure support for "playful peer interactions and social initiations" (p. 1196) for children with autism spectrum disorders and their nonimpaired peers. Such a finding highlights the potential of a carefully considered physical playground to foster peer interaction. 


\section{Playgrounds as inclusive spaces for children}

Inclusion is seen as the major benefit and desired outcome of accessible community playgrounds, particularly for children with impairments (Dunn, Moore \& Murray, 2003; John \& Wheway, 2004; Webb, 2003; Yuill et al., 2007). Underpinned by the social model of disability, a theoretical perspective which has emerged from the disability movement in the United Kingdom, and which has been developed by disabled people themselves, these studies draw on discourses of inclusion and equity, and respect for the human rights of children with impairments. Consultation with playground users, both parents and children, as well as with local council playground providers, is a feature of these studies (Dunn, Moore \& Murray, 2003; John \& Wheway, 2004; Webb, 2003). The relationship between disability and community playgrounds is specifically examined in an attempt to provide guidance to playground providers to assist them in conceptualising and designing playgrounds that provide access to children with impairments so that they can play alongside their non-impaired peers. Dunn and Moore (2005) report that when they interviewed playgrounds amenities officers, some suggested that it might be "useful to think about disability as what a child experiences if they encounter disabling attitudes and disabling environments” (p. 340). This way of thinking about disability is the essence of the social model of disability.

Prellwitz and Skar (2007), in a Swedish study, interviewed 20 children with different abilities with the aim of gaining an understanding of how, from a child's perspective, children use playgrounds to engage in creative and social play. The researchers found that, for all the children who participated in the study, playgrounds serve as a "reference point” (p. 144), challenge their physical abilities and give them opportunities to interact socially and engage in role playing. For the children with physical impairments, playgrounds provided "limited accessibility, usability, and did not support interaction with peers" (p. 144). Prellwitz and Skar emphasise the importance, as articulated by their research participants, of playgrounds being used not only for physical play but also as a "meeting place where play and social interaction take place" (p. 153). The researchers advance an argument for the necessity of Universal Design for all public playgrounds. It is worth noting that in studies that use methodologies that consult children, such as those by Moore (1986), Prellwitz and Skar (2007), Sandburg (2002) and Woolley (2006), the social relational aspects of children's play are foregrounded in the data and findings, ahead of the functional and mechanical aspects of play on a playground.

\section{Universal design}

The concept of Universal Design (UD) is central to an emerging architectural movement that is beginning to extend into the arena of playground development and provision. As a social movement, UD calls for recognition of and catering for human diversity in the design of environments and objects (Connell \& Sandford, 1999; Imrie, 2004; Skulski, 2007). Connell, Jones, Mace, Mueller, Mullick, Ostroff and their colleagues (2008), provide a useful definition of UD as "the design of products and 
environments to be usable by all people, to the greatest extent possible, without the need for adaptation or specialised design” (p. 1).

In UD, the aim is to recognise human diversity and to find ways for all people to access and use environments and objects in inclusive ways. Imrie (2004) explains how, in UD, impairment is seen as being not unique to a specific population but intrinsic to the human condition. Impairment, then, as a characteristic of a diverse human society, needs to be factored into design. According to Connell and her research team (Connell et al., 2008), UD is underpinned by seven foundation principles that serve as a guide towards ensuring inclusiveness in design that caters for all human variations. The principles are: equitable use, flexibility in use; simple and intuitive; perceptible information; tolerance for error; low physical effort; and size and space for approach and use. In Table 1, these UD principles are reproduced along with the descriptions for each principle as provided by Connell and her colleagues (2008).

Table 1. Universal Design Principles

\begin{tabular}{|l|l|}
\hline \multicolumn{1}{|c|}{ Principle } & \multicolumn{1}{c|}{ Description } \\
\hline Equitable use & The design is useful and marketable to people with diverse abilities. \\
\hline $\begin{array}{l}\text { Flexibility in } \\
\text { use }\end{array}$ & $\begin{array}{l}\text { The design accommodates a wide range of individual preferences and } \\
\text { abilities. }\end{array}$ \\
\hline $\begin{array}{l}\text { Simple and } \\
\text { intuitive }\end{array}$ & $\begin{array}{l}\text { The use of the design is easy to understand regardless of the user's } \\
\text { experience, knowledge, language skills or current concentration level. }\end{array}$ \\
\hline $\begin{array}{l}\text { Perceptible } \\
\text { information }\end{array}$ & $\begin{array}{l}\text { The design communicates necessary information effectively to the } \\
\text { user, regardless of ambient conditions or the user's sensory disabilities. }\end{array}$ \\
\hline $\begin{array}{l}\text { Tolerance for } \\
\text { error }\end{array}$ & $\begin{array}{l}\text { The design minimises hazards and the adverse consequences of } \\
\text { accidental or unintended actions. }\end{array}$ \\
\hline $\begin{array}{l}\text { Low physical } \\
\text { effort }\end{array}$ & $\begin{array}{l}\text { The design can be used efficiently and comfortably and with a } \\
\text { minimum of fatigue. }\end{array}$ \\
\hline $\begin{array}{l}\text { Size and space } \\
\text { for approach } \\
\text { and use }\end{array}$ & $\begin{array}{l}\text { Appropriate size and space is provided for approach, reach, } \\
\text { manipulation and use regardless of the user's body size, posture or } \\
\text { mobility. }\end{array}$ \\
\hline
\end{tabular}

Source: Connell et al., 2008, pp. 1-3.

UD principles aim to provide a single product or environment that can be utilised by all potential users without segregating or stigmatising anyone. All users, not just those with impairments, should benefit from using such designs as Imrie (2004) explains: "Universal Design ... seeks to integrate the accommodation of disability with the basic concept of the design by sensitising the environment to the broadest possible range of body shapes, dimensions and movements” (p. 280). In contrast, conventional design approaches, according to Imrie "fail to recognise bodily and physiological diversity" and are often based on technical standards and dimensions that rely on a notion of the "normal” body (p. 281). Imrie describes this normal body as "little more than an object 
with fixed, measurable parts; it is neutered and neutral, that is, without sex, gender, race or physical difference” (p. 281). Conventional design, in other words, uses normative guidelines that fail to consider that the needs or requirements of some people may not fall within these narrow guidelines. Most traditional playgrounds feature conventional design approaches, and, although they sometimes make allowances for different sized children (within "normal” growth and development patterns), the design still fails to cater for children who fall outside identified norms for size or ability. Conventional design (which is sometimes referred to as "inaccessible design"), can disable and marginalise some individuals on the basis of their size or ability. Proponents of UD, as Connell and Sandford (1999) explain, are particularly critical of "compensatory approaches” (p. 37) to design that provide special accessibility provision for disabled people. Connell and Sandford recognise two types of compensatory approaches to design. In the first of these, accessibility is added "to otherwise inaccessible objects and standard designs” to compensate disabled people for their functional limitations (p. 37). This is sometimes referred to as "retrofitting." The second compensatory approach to design is described as offering "segregated accessible features" (Center for Universal Design, 2008) so that objects are purpose built exclusively for those with impairments. "Segregated accessible" designs are sometimes criticised for being "ugly" and expensive and for creating stigma for the people who use them (Center for Universal Design, 2008; Imrie, 2004). Most importantly, in the principles of inclusion, such design is seen as "demeaning” (Imrie, 2004, p. 281) because it publicly highlights a person's impairment (Center for Universal Design, 2008; Imrie, 2004). Although both types of compensatory approaches to design (the added-on "retrofitting" and the "segregated accessible” specialist designs) recognise that people with impairments need to be accommodated in order to use objects and environments, unlike UD, neither approach provides for genuine accessibility. Furthermore, both approaches neglect to address the political issue of inclusion of people with impairments. The distinctions between UD, compensatory approaches to design and conventional design, are important because they help to explain how playground provision can be informed by design approaches that are underpinned by differing social and political assumptions.

\section{The legislative base for inclusive playgrounds in Australia}

Having explained different design approaches, and how each contributes to accessibility, the relevant legislation and policy governing playground provision in Australia and the somewhat contrasting approaches in the United States of America and the United Kingdom will be discussed.

In Australia, as is the case in Canada (Yantzi, Young \& McKeever, 2010), legislation governing accessibility of public buildings does not extend to playgrounds as it does, for instance, in the United States of America. Legislation and policy in Australia that governs design and provision of playgrounds is applied within the Australian three-tier system of government at Federal, State and local levels. At the Federal level, the Commonwealth Disability Discrimination Act 1992 (DDA) makes discrimination on the basis of impairment unlawful (Australian Government Attorney General's Department, 
2008). The DDA applies to people with impairments as well as carers of people with impairments. In the State of Victoria, in the south east of Australia, the Equal Opportunity Act 2010 (Victorian Equal Opportunity and Human Rights Commission, 2011) seeks to promote equality of opportunity and to eliminate discrimination and harassment that results from various personal "attributes," including impairment, and to assist in the resolution of complaints of discrimination. The responsibility for policies that govern the accessibility of public facilities, including playgrounds, lies at local government level under legislative responsibilities derived from the DDA. In an attempt to provide playground access to community members with impairments, local councils are responsible for interpreting and applying policies. The provision of facilities and services that can be used by a wide range of community members is considered critical in the planning, development and implementation of local community playgrounds. At the same time, such an approach is relatively open to interpretation (and translation to practice) as to what specifically constitutes accessibility in playgrounds.

\section{Formal guidelines for accessibility in playgrounds}

Regulations supported by the Australian Standards for Playgrounds and Play Equipment (Standards Australia, 2004) form the basis of local government risk-management strategies. They pertain to safety requirements and test methods (general standards and tests for specific generic pieces of equipment such as slides) and also surfacing, development, installation, inspection, maintenance and operation of playgrounds, as well as supervision and risk management. The Australian standards for access and mobility apply to buildings in general, but not specifically to playgrounds. The standards inform design for access and mobility, physical disabilities and tactile indicators in new buildings in Australia (Standards Australia, 2010). Most of the interest in designing inclusive playgrounds in Australia has come from a small number of architects who work in private industry. While such architects have made some attempt to share their designs and ideas with the wider playground provision community through literature and public forums (for example, Bishop, 2004; Robbé, 2004), the concept of accessibility is still open to interpretation depending on how "impairment effects” (Thomas, 1999) and access problems are understood by the individual designers and then accepted and implemented by specific playground providers in each case.

In Australia, playgrounds are provided by local councils, or by schools or private organisations that draw on a number of often-conflicting considerations in making their decisions about what type of equipment should be provided. Such organisations are subject to inhibiting factors such as legal issues, various government policies and building and budgetary constraints, as well as community implementation and public relations considerations, all of which impact on the type of playground that is eventually provided. Boyatzis (1987), for example, identifies "indestructibility" and "low maintenance requirements" (p. 101) as two factors which often have a bearing on public playground provision. It is important to understand that there are as yet no formal guidelines or definitions that clearly state what accessibility in a playground is/should 
be. The term "inclusive playground" is gaining acceptance in Australia, and indeed worldwide, to describe play spaces that are purpose-designed to include all members of the community (irrespective of age, ability or any other perceivable difference) in the experience of play in a playground. In 2012 in Canberra, Australia, and in what was considered a world-first event, a group of "leading disability advocates, local government representatives and experts” from around Australia were brought together to collaborate on draft "Inclusive play guidelines" using funds from a federal government grant. The author of this paper was one of the invited delegates. Hopefully when these guidelines are published towards the end of 2012, a clear way forward with respect to inclusive play provision will be available for playground providers, designers and others from Australian communities.

British and European playground standards, like those in Australia, "contain no advice on accessibility for disabled children to either playgrounds or equipment" (John \& Wheway, 2004). However, in the United Kingdom, guides to making playgrounds more accessible have been released by the Office of the Deputy Prime Minister, Developing accessible play space: a good practice guide (Dunn, Moore \& Murray, 2003), the National Playing Fields Association (NPFA), Can play, will play: disabled children and access to outdoor playgrounds (John \& Wheway, 2004), and The Royal Society for the Prevention of Accidents (RoSPA), Playgrounds for children with special needs (Hicks \& Heseltine, 2001). The aim of these guides is to focus attention on planning and design considerations for “accessible” playgrounds. All offer design ideas for planning new playgrounds or modifying existing playgrounds. These documents address requirements of the Disability Discrimination Act (DDA) (UK). In the United States of America, mandated design standards incorporate normative guidelines to dictate how playgrounds must be physically designed and built to cater for users who have impairments. United States' laws governing playground construction as required by the Americans with Disabilities Act Accessibility Guidelines (ADAAG, 1990) and the United States Architectural and Transport Barriers Compliance Board (supplementary accessibility guidelines for newly constructed and altered play areas (2001) (ADAAG, 2004)), specify minimum requirements for access to play areas for children and adults with impairments and their carers.

The US accessibility guidelines for newly constructed and altered play areas tend to favour making built environments wheelchair accessible by providing mainly for the removal of physical barriers that limit access for those with impairments, as pointed out by Malkusak, Schappet and Bruya (2002) and Webb (2003). Some critics of these guidelines argue that they cater predominantly for children who use wheelchairs, but have little provision for the needs of children who have other impairments. Also of concern is the issue that the law requires "minimum standards" only (Wellhousen, 2002) and playground design tends to become "a numbers game” (Skulski, 2007) focusing on providing compliance and counting particular essential features to ensure compliance. Physical accessibility becomes the aim, not providing for fun or play appeal for children or for integrated play for people with a wide range of impairments 
(John \& Wheway, 2004; Malkusak, Schappet \& Bruya, 2002; Thompson, Hudson \& Bowers, 2002; Webb, 2003). The need for play activities that are developmentally appropriate, or quality play experiences that stimulate imagination, creativity or peer play, is not addressed by these guidelines.

\section{Child-centred and community approaches to inclusive play on playgrounds}

Applying legislated technical approaches is not the only, nor necessarily the best, way of ensuring accessibility in playgrounds for children with impairments. John and Wheway (2004), in their UK report mentioned previously, Can play, will play, reject the idea of mandated design standards for accessibility such as those in place in the USA. These authors state, “sadly too much of the debate about children's freedom to play has revolved around treatment or directed activity, rather than play, and around technical modifications to equipment, rather than children playing” (p. 12). In their report on how playgrounds can best meet the requirements of the DDA (UK), John and Wheway argue that the quality of the participation in play by all children should take precedence over merely being able to be physically present in a playground. Their report drew on their own research that involved an unspecified number of consultations with children with impairments, their parents and teachers and on the authors' observation of children with impairments playing in their school and local community playgrounds. John and Wheway state that their findings challenge the assumption that simply providing inclusive playgrounds will ensure that disabled children use them. They argue for a child-centred approach that places importance on opportunities for children's inclusive peer play in preference to standards-driven, technical approaches. John and Wheway privilege the concept of inclusion and favour attempts to enable children with impairments to "play freely with their friends" (p. 14). They conclude their study by stating that "making the playground accessible is ... about overcoming fears and building understanding and relationships" (p. 20). Here they refer to the importance of fostering relationships among community members so that disabled children and their families can overcome their apprehension of using shared community environments. Inclusion needs to be considered broadly. Rather than focusing on attempts to ensure access to each individual place or piece of equipment in a playground for a broad range of users with a variety of abilities or needs, the primary aim should be to ensure that all children can gain access to the "social experience of play" (Dunn \& Moore, 2005, p. 341). Playgrounds which provide physical barriers to some children, preventing them from entering a playground, fail dismally in this respect. A Canadian study (Yantzi et al, 2010) describes the concept of "Playability," as used by the Ontario Parks Association. Playability requires a playground to offer a variety of play activities for children with impairments and, further, that purpose-provided play components for children with impairments must be intermingled with non-accessible components.

Making social connections at a community level is seen as central for creating community environments in sustainable communities. Beckman et al. (1998), in a US study that aims to identify facilitators and barriers to community inclusion, conducted interviews with families of children with and without impairments. They conclude from 
their analysis of their interview data that a connected community focus is more important than technical requirements for children's outdoor environments. Beckman and her colleagues support an approach in which community connection and welcoming messages are conveyed to children with impairments and their families. For these authors, a broad vision of a connected community, which extends beyond merely providing programmes and equipment in individual settings, is required.

A relational community approach is also favoured by Corkery (2004), who sees playgrounds as part of what she calls a "sustainable" community. Inclusion is an underpinning philosophy of sustainable communities (Dunn \& Moore, 2005). In contributing to a sustainable community, playgrounds are important as places where children's relationships are forged and their values and attitudes are shaped by interactions with both familiar people and relative strangers. Corkery (2004) explains the powerful educational effects of playgrounds and the built environment generally:

Play environments, including playgrounds, are in the public domain and are gathering places where children are likely to have some of their initial interactions with other children who are unknown to them. Therefore these are the places where children have the opportunity to be socialised with the idea of community life, outside the more familiar domains of home and school (p. 111).

From Beatley and Manning's (1997) list of characteristics of the social qualities of sustainable communities, Corkery (2004, p. 111) selects four factors that she believes have particular relevance to sustainable play environments. Sustainable play environments "have regard for the quality of life for current and future generations; are expressive of a sense of place; are equitable and just for all users" (in particular they ensure physical access and social opportunity to all community members): and "are planned and designed to respond to and underpin the concept of community” (Corkery, 2004, pp. 112-113). Following Corkery's argument, a sustainable community approach to playground provision would seem to centre on social justice and equitable use of playgrounds, achieving quality of life for all playground users and fostering community connectedness.

\section{Summary and conclusions}

To promote participation and self-determination for all children, it is vital that when conceptualising and constructing playgrounds, consideration is given to ensuring that everyone can be included in play. As Soresi, Nota, and Wehmeyer (2011) point out, "real participation and inclusion in the community does not just happen ... but requires the commitment of all community members" (p. 16). Conventional playgrounds are unlikely to be inclusive and therefore some thought must be given to how particular configurations and constructions might include some people and exclude others from the experience of play. 
It is clear that, within the confines of legislation and policies that shape playground construction and provision, there are alternative views about how to best approach inclusion for children with impairments. The author of this paper does not seek to make a case for the desirability of inclusive playground guidelines, or to support the principles of UD. The paper does highlight the guidelines that are in place, as well as the vagaries that apply to providing for accessibility and inclusion in playground sites. In addition, it is important to understand how inclusive playground provision is subject to a variety of policies, rules, regulations and interpretations.

The concept of UD, because of its philosophical congruence with the principle of inclusion, would seem to have utility for underpinning the design of public playgrounds. Both UD and inclusion address the political and social issues associated with the exclusion and consequent marginalisation of children and adults with impairments from and within conventional playgrounds. According high priority to inclusion in play environments, as argued by several writers and reported in this paper, is an important political objective and a priority which must be applied to all children's playgrounds to facilitate healthy, vibrant, fair and connected communities. 


\section{References}

Americans with Disabilities Act, Accessibility Guidelines (ADAAG). (1990).

Americans with Disabilities Act, Access Guidelines (ADAAG). (2004). Retrieved from http://www.accessboard.gov/adaag/html/adaag.htm

Australian Government Attorney General’s Department. (2008). Disability

Discrimination Act 1992. Retrieved from

http://www.comlaw.gov.au/comlaw/management.nsf/lookupindexpagesbyid/IP20040 1406?OpenDocument

Ball, D., Gill, T., \& Spiegal, B. (2008). Managing risk in play provision:

Implementation guide. UK: Department for Culture, Media and Sport (DCMS).

Retrieved from http://www.playengland.org.uk/media/172644/managing-risk-inplay-provision-implementation-guide.pdf

Beatley, T., \& Manning, K. (1997). The ecology of place: Planning for environment, economy and community. Washington DC: Island Press.

Beckman, P., Barnwell, D. Horn, E., Hanson, M., Gutlerrez, S., \& Lieber, J. (1998). Communities, families and inclusion. Early Childhood Research Quarterly, 13(1), 125-150.

Beckman, P., \& Hanson, M. (2002). Community participation of children with disabilities. In S. Odom (Ed.), Social relationships of children with disabilities and their peers in inclusive preschool classrooms (pp. 109-119). New York: Teacher's College Press.

Berry, P. (2001). Playgrounds that work: Creating outdoor play environments for children. Baulkham Hills, NSW: Pademelon Press.

Bishop, J., \& Curtis, M. (Eds.). (2001). Play today in the primary school playground: Life, learning and creativity. Buckingham, UK: Open University Press.

Bishop, K. (2004). Designing play activities for children with disabilities: How should this influence the detail of playground design? In Proceedings of the Kidsafe National Playground Conference, Brighton Beach, Australia, 22-24 March 2004 (pp. 149-156). Sydney, NSW, Australia.

Boyatzis, C. J. (1987). The effects of traditional playground equipment of pre-school children's dyadic play in schools (pp. 101-109). In G. Fine (Ed.), Meaningful play, playful meaning. Champaign, Illinois: Human Kinetics Publishers, Inc.

Bristow, J. (2004). Playground squabbles. Retrieved from http://www.spikedonline.com/site/article/8421/ 
Center for Universal Design. (2008). About UD: Universal Design history. Retrieved from http://www.ncsu.edu/www/ncsu/design/sod5/cud/about_ud/udhistory.htm

Connell, B. R., Jones, M., Mace, R., Mueller, J., Mullick, A., \& Ostroff, E., et. al. (2008). About UD: Universal Design principles. Retrieved July 3, 2008, from http://www.ncsu.edu/project/design-projects/udi/center-for-universal-design/theprinciples-of-universal-design/

Connell, B. R., \& Sandford, J. A. (1999). Research implications of universal design. In E. Steinfeld \& G. S. Danford (Eds.), Enabling environments (pp. 35-56). New York: Klewer Academic.

Corkery, L. (2004). Play environments in the sustainable community. In Proceedings of the Kidsafe National Playground Conference, Brighton Beach, Australia, 22-24 March 2004 (pp. 108-118). Sydney, NSW, Australia.

Dunn, K., \& Moore, M. (2005). Developing accessible play space in the UK: A social model approach. Children, Youth and Environments. 15(1), 332-346.

Dunn, K., Moore, M., \& Murray, P. (2003). Developing accessible play space: A good practice guide. Retrieved from http://www.communities.gov.uk/documents/communities/pdf/131052.pdf

Factor, J. (2004). Tree stumps, manhole covers and rubbish tins: The invisible playlines of a primary school playground. Childhood, 11(2), 142-154.

Finkelstein, V. (2004). Representing disability. In J. Swain, S. French, C. Barnes \& C. Thomas (Eds.), Disabling barriers - enabling environments (2nd ed., pp. 13-20). London: SAGE Publications.

Gill, T. (2007). No fear: Growing up in a risk averse society. London: Calouste Gulbenkian Foundation.

Henniger, M. (1994). Planning for outdoor play. Young children, 49(4), 10-15.

Hicks, J., \& Heseltine, P. (2001). Playgrounds for children with special needs. London: RoSPA.

Howard, D. (1955). Folklore of Australian children. Journal of Education, 2(1), 30-35.

Howard, D. (1965). Folklore of Australian Children, Keystone Folklore Quarterly. 3, 99-115.

Hudson, S. D., Thompson, D., \& Olsen, H. (2005). How SAFE are school and park playgrounds? A progress report. JOPERD: The Journal of Physical Education, Recreation \& Dance, 76(1), 16-20. 
Imrie, R. (2004). From universal to inclusive design in the built environment. In J. Swain, S. French, C. Barnes \& C. Thomas (Eds.), Disabling barriers - enabling environments (2nd ed., pp. 279-284). London: SAGE Publications.

John, A., \& Wheway, R. (2004). Can play, will play. London: National Playing Fields Association (NPFA).

Keefe, M. (2007). The inclusive society. In M. Keefe \& S. Carrington (Eds.), Schools and diversity (pp. 17-30). French's Forest, NSW: Pearson Education Australia.

Malkusak, T., Schappet, J., \& Bruya, L. (2002). Turning accessible playgrounds into fully integrated playgrounds: Just add a little essence. Parks and Recreation, 37(4), 66-71.

Martin, J., \& Cooper, C. D. (2005). Playground safety in South Western Sydney. Journal of Paediatric Child Health, 41, 587-591.

Monash University Accident Research Centre. (2005). Consumer product-related injury (1): Playground equipment and trampolines. Hazard, 61, 1-24.

Moore, R. (1986). Childhood's domain: Play and place in child development. London: Croom Helm.

Moore, R. (2003). Book review: Designing for play. Children Youth and Environments. 13(1), 1-6.

Nikolaraizi, M., Kumar, P., Favazza, P., Sideridis, G., Koulousiou, D., \& Riall, A. (2005). A cross-cultural examination of typically developing children's attitudes towards children with special needs. International Journal of Disability, Development \& Education, 52(2), 101-119.

Nind, M., \& Seale, J. (2009). Concepts of access for people with learning difficulties: Towards a shared understanding. Disability \& Society, 24(3), 273-287.

Opie, I., \& Opie, P. (1959). The lore and language of schoolchildren. Oxford: Oxford University Press.

Opie, I., \& Opie, P. (1969). Children's games in street and playground. Oxford: Oxford University Press.

Pancella, P. (2004). Playground safety. Chicago, Ill: Heineman.

Prellwitz, M., \& Skar, L. (2007). Usability of playgrounds for children with different abilities. Occupational Therapy International, 14(3), 144-155.

Reid, D. K., \& Valle, J. W. (2004). The discursive practice of learning disability: Implications for instruction and parent-school relations. Journal of learning 
disabilities, 37(6), 466-481.

Robbé, F. (2004). Designing for delight: Creative playground solutions, no matter what. In Proceedings of the Kidsafe National Playground Conference, Brighton Beach, Australia, 22-24 March 2004 (pp. 96-106). Sydney, NSW, Australia.

Russell, H. (1986). Play and friendships in a multi-cultural playground. Melbourne: Australian Children's Folklore Publications.

Sandburg, A. (2002). Children's concepts of teachers' ways of relating to play. Australian Journal of Early Childhood, 27(4), 18-22.

Skulski, J. (2007). Designing for inclusive play: Applying the principles of universal design to the playground. Bloomington, IN: National Center on Accessibility. Retrieved from http://www.ncaonline.org/?q=node/331

Soresi, S., Nota, L., \& Wehmeyer, M. (2011). Community involvement in promoting inclusion, participation and self-determination. International Journal of Inclusive Education, 15(1), 15-28.

Stalker, K., \& Connors, C. (2003). Children's perceptions of their disabled siblings: "She's different but it's normal for us.” Children \& Society, 18(3), 218-230.

Standards Australia. (2004). Playground equipment series. AS4685. Council of Standards Australia.

Standards Australia. (2010). Design for access and mobility series. AS1428. Council of Standards Australia.

Thomas, C. (1999). Female forms: Experiencing and understanding disability. Buckingham, UK: Open University Press.

Thompson, D., Hudson, S. D., \& Bowers, L. (2002). Play areas and the ADA: Providing access and opportunities for all. Journal of Physical Education, Recreation and Dance, 73(2), 37-41.

Topping, K., \& Maloney, S. (Eds.). (2005). The RoutledgeFalmer reader in inclusive education. London: RoutledgeFalmer.

Union of the Physically Impaired Against Segregation (UPIAS). (1975). Fundamental principles of disability. London: UPIAS. Retrieved from http://www.leeds.ac.uk/disabilitystudies/archiveuk/UPIAS/fundamental\%20principles.pdf

Victorian Equal Opportunity and Human Rights Commission. (2011). Equal Opportunity Act Quick Guide - July 2011. Retrieved from 
http://www.humanrightscommission.vic.gov.au/index.php?option=com_k2\&view=it em\&id=1448:equal-opportunity-act-2010-quickguide\&Itemid=687\#!!ts=1344490565965!

Webb, R. (2003). Public play provision for children with disabilities. Retrieved from http://www.playireland.ie/news.asp

Wellhousen, K. (2002). Outdoor play, every day: Innovative play concepts for early childhood. Albany, NY: Delmar.

Widdows, J. (1997). A special need for inclusion. London: The Children's Society.

Woolley, H. (with Armitage, M., Bishop, J. Curtis, M., \& Ginsborg, J.). (2006). Going outside together: Good practice with respect to the inclusion of disabled children in primary school playgrounds. Children's Geographies, 4(3), 303-318.

Woolley, H., \& Lowe, A. (2012). Exploring the relationship between design approach and play value of outdoor play spaces. Landscape Research. 1, 1-22.

Yantzi, N., Young, N., \& McKeever, P. (2010). The suitability of school playgrounds for physically disabled children. Children's Geographies, 8(1), 65-78.

Yuill, N., Strieth, S., Roake, C., Aspden, R., \& Todd, B. (2007). Brief report: Designing a playground for children with autistic spectrum disorders. Journal of Autism and Developmental Disorders, 37(6), 1192-1196. 